Journal of Environmental Sciences (JES)

Institute of Environmental Studies and Research, Ain Shams University

Shrief M. Salah El Deen et al.

\title{
ENVIRONMENTAL RISK FACTORS OF NOSOCOMIAL INFECTIONS IN NEUROLOGICAL INTENSIVE CARE
}

\section{UNIT}

\author{
Shrief M. Salah EI Deen ${ }^{(1)}$; Mahmoud S. Elbokhary ${ }^{(2)}$ \\ and Hwaida M. Kamal ${ }^{(3)}$
}

1) Post Grad. Student Institute of Environmental Studies and Research Ain shams University 2) Institute of Environmental Studies and Research Ain shams University 3) Faculty of Medicine, Baha University

\begin{abstract}
Background: The Centers of Disease Control and Prevention (CDC) estimate that 2 million patients develop hospital-acquired infection annually and as many as 88,000 die as a result, adding an estimated $\$ 5$ billion to the annual national health care costs. Object: To evaluate risk factors and methods of infection control in surgical site infections in postoperative neurosurgical patients.

Methods: This study was prospective, uncontrolled and observational study conducted on patients with postoperative neurosurgical operation and admitted to Intensive Care Unit postoperatively. The study was done in Al-Azhar university hospitals from March 2017 to March 2018. The study aim was. Analysis of data was done by IBM computer using SPSS (statistical program for social science version 25).

Results: In the study sample, the mean age and standard deviation (SD) were 42.5 years \pm 19 . 1 . Female patients were about $40 \%$. Most male patient were above median age of the sample (37.8 years). The overall admission period includes pre-ICU admission, ICU admission and post-ICU admission. The mean and standard deviation of overall admission was 43.7 day \pm 5.5 . From the whole study sample, nosocomial infection was estimated to be $88.4 \%$ of cases (69 patients). Postoperative mortality among cases was $36 \%$. The rest of cases were either referred or discharged to ward. Comorbid conditions may
\end{abstract}


Journal of Environmental Sciences (JES)

Institute of Environmental Studies and Research, Ain Shams University

Shrief M. Salah El Deen et al.

present as single factor or multiple factors in the same patient. Patients with nosocomial infections were found to have two or more comorbid conditions while infection-free cases were found to have no or at least one factor in a statistically significant association. It has been found that most cases with traumatic brain injury and hemorrhagic stroke had nosocomial infection (74\%). Both types mentioned previously had longer ICU stay. It has been found that nosocomial infection is commonly predominant in traumatic brain injury and intracranial hemorrhage cases (ICH).

Nosocomial infections were found to be either single or multiple infections in the same person. Most of infections were; respiratory tract infection, urinary tract infection or septicemia. When the entire study sample was subjected to logistic regression analysis, age, diagnosis and hospital stay, necessity for ventilation, low Glasgow Coma Scale (GCS), high temperature, high humidity and low karnofsky were found to be significantly independently predictive of postoperative nosocomial infection. Among these patients, type and timing of operative intervention and environmental factors did not significantly affect outcome.

Conclusion: There are many risk factors of nosocomial infection in hospitalized neurosurgical treated, which requires strict monitor, including the development of various effective prevention measures and check of their implementation as well as effectiveness, to reduce the incidence of hospital infection.

Keywords: nosocomial infection, environmental factors

\section{INTRODUCTION}

The term "nosocomial infection" can be used interchangeably with "Hospital Acquired Infection." The Centers of Disease Control and Prevention (CDC) defines a Hospital Acquired Infection (HAI) as a localized or systemic condition resulting from an adverse reaction to an infectious agent (s) or toxin(s) (Abulhasan et al., 2018). An infection is considered HAI if it develops in a patient who has been hospitalized for 48 to 72 hours and no 
Journal of Environmental Sciences (JES)

Institute of Environmental Studies and Research, Ain Shams University

Shrief M. Salah El Deen et al.

evidence that the infection was incubating at the time of admission. The CDC estimates that two million patients develop HAIs annually and as many as 88,000 die as a result, adding an estimated $\$ 5$ billion to the annual national health care costs (Beer et al., 2010).

The spread of nosocomial infections by traditional means such as lack of hand hygiene compliance goes as far back as the 1800s (Cardoso et al., 2015). By reviewing maternal deaths in two divisions of the maternity department in Vienna, it was noted that more than $10 \%$ of women died following childbirth when the baby was delivered by a physician or student in the first division, compared to a lower rate of $3 \%$ of maternal death when babies were delivered by a midwife (Felming et al., 2010). These differences in death rates could be explained by the fact that medical students and physicians performed autopsies without disinfecting their hands before attending to the next patient. In other words, the physicians were the source of infection to the patients (Ducel and Fabry, 2002).

The purpose of this research was to evaluate risk factors and methods of infection control in surgical site infections in postoperative neurosurgical patients.

\section{PATIENTS AND METHODS}

This is a prospective study over one year. Institutional Review Board approval was taken prior to launch the study. This study was conducted on 69 patients from a total of 78 with postoperative neurosurgical operation and

Vol.(49); Iss.(12); No.(2); Dec..2020 
Journal of Environmental Sciences (JES)

Institute of Environmental Studies and Research, Ain Shams University

Shrief M. Salah El Deen et al.

admitted to ICU postoperatively. The study was done in Al-Azhar University hospitals from March 2017 to March 2018. 
Journal of Environmental Sciences (JES)

Institute of Environmental Studies and Research, Ain Shams University

Shrief M. Salah El Deen et al.

\section{Inclusion criteria}

1. Above 18 year

2. Both genders

3. Patient did neurosurgical operation and admitted to neuro-ICU postoperatively.

\section{Exclusion criteria}

1. Previous source of infection

2. Patient did surgery outside the hospital.

3. Immunocompromised patient.

\section{Preoperative record:}

1. Complete history taking, general and neurological examination and full labs.

2. Demographic criteria

3. Previous condition

4. Nutritional state

5. Neurosurgical disease

6. Preoperative medication and antibiotics

7. Duration of pre-operative admission

8. Comment on drapping

9. Surgical site scrapping

10. Operative preparation

11. Method of sterilization 
Journal of Environmental Sciences (JES)

Institute of Environmental Studies and Research, Ain Shams University

Shrief M. Salah El Deen et al.

12. Document use of personal protective

13. Operative time

14. Blood transfusion

15. Postoperative ICU admission period

16. Total hospital admission

17. Postoperative antibiotics

All patients underwent specimen elaboration from the following sites:

1. IV cannulas

2. Central venous pressure lines

3. Pipes of mechanical ventilation

4. Endotracheal tube

5. Chest tube

6. Foley catheter

7. Mask

In addition, microbiological assessment by smears were recruited for the following sites:

1. Mouth

2. Surgical site

3. Bed sores

Smears were taking also from the following sites:

1. Physician and nurses room

2. Water sources

3. Air conditioners

40 
Journal of Environmental Sciences (JES)

Institute of Environmental Studies and Research, Ain Shams University

Shrief M. Salah El Deen et al.

Data Analysis: Analysis of data was done by IBM computer using SPSS (statistical program for social science version 25).

\section{RESULTS}

This study will be conducted on patients with postoperative neurosurgical operation and admitted to ICU postoperatively. The study was done in AlAzhar university hospitals from March 2017 to March 2018. In our study, we recruited 78 patients admitted to neurological intensive care unit over one year.

Cases which have been categorized with nosocomial infection were 69 cases $(88.4 \%)$. Those with no infections were called infection-free patients. The latter group were only nine patients (11.6\%).

Demographic characteristics

The mean age and standard deviation (SD) were 42.5 years \pm 19.1 . Fortyseven patients were male $(60.25 \%)$. Most male patient were above median age of the sample (37.8 years).

* Hospital admission

The overall admission period included pre-ICU admission, ICU admission and post-ICU admission. The mean and standard deviation of ICU admission period was 43.7 day \pm 5.5 . The distribution of values was not normal. Two patients were regarded as outliers with longstanding period in 
Journal of Environmental Sciences (JES)

Institute of Environmental Studies and Research, Ain Shams University

Shrief M. Salah El Deen et al.

ICU up to 3 months. The Table 1 summarizes the hospital admission periods in our study.

Table 1: Hospital admission periods in days

\begin{tabular}{|l|l|l|}
\hline Admission & Mean (SD) & $95 \%$ CI \\
\hline Pre-ICU* & $5.6(.25)$ & $3.5-7.7$ \\
\hline ICU* & $43.7(5.5)$ & $26-61.4$ \\
\hline Post-ICU* ward & $16.3(4.4)$ & $11.5-21.1$ \\
\hline
\end{tabular}

*ICU: Intensive Care Unit

It has been found that cases with positive infection (nosocomial infections) were statistically significant.

Table 2: Period of stay in ICU*

\begin{tabular}{|c|c|c|c|}
\hline Infection & Mean (SD), Range & P value & Significance \\
\hline Yes & $51.3(14.7), 17-75$ & & \\
\hline No & $12(.48), 5-19$ & 0.0001 & HS \\
\hline
\end{tabular}

*ICU: Intensive Care Unit

* Comorbidities and Mortality

Diabetes mellitus was found in $24 \%$ of cases, fourteen percent of patient had elevated lipid profile (dyslipidemia). Hypertension was found in $21 \%$ of cases. The table below summarizes our findings (see table 3).

From the whole study sample, nosocomial infection was estimated to be $88.4 \%$ of cases (69 patients). Postoperative mortality among cases was $36 \%$. The rest of cases were either referred or discharged to ward. 


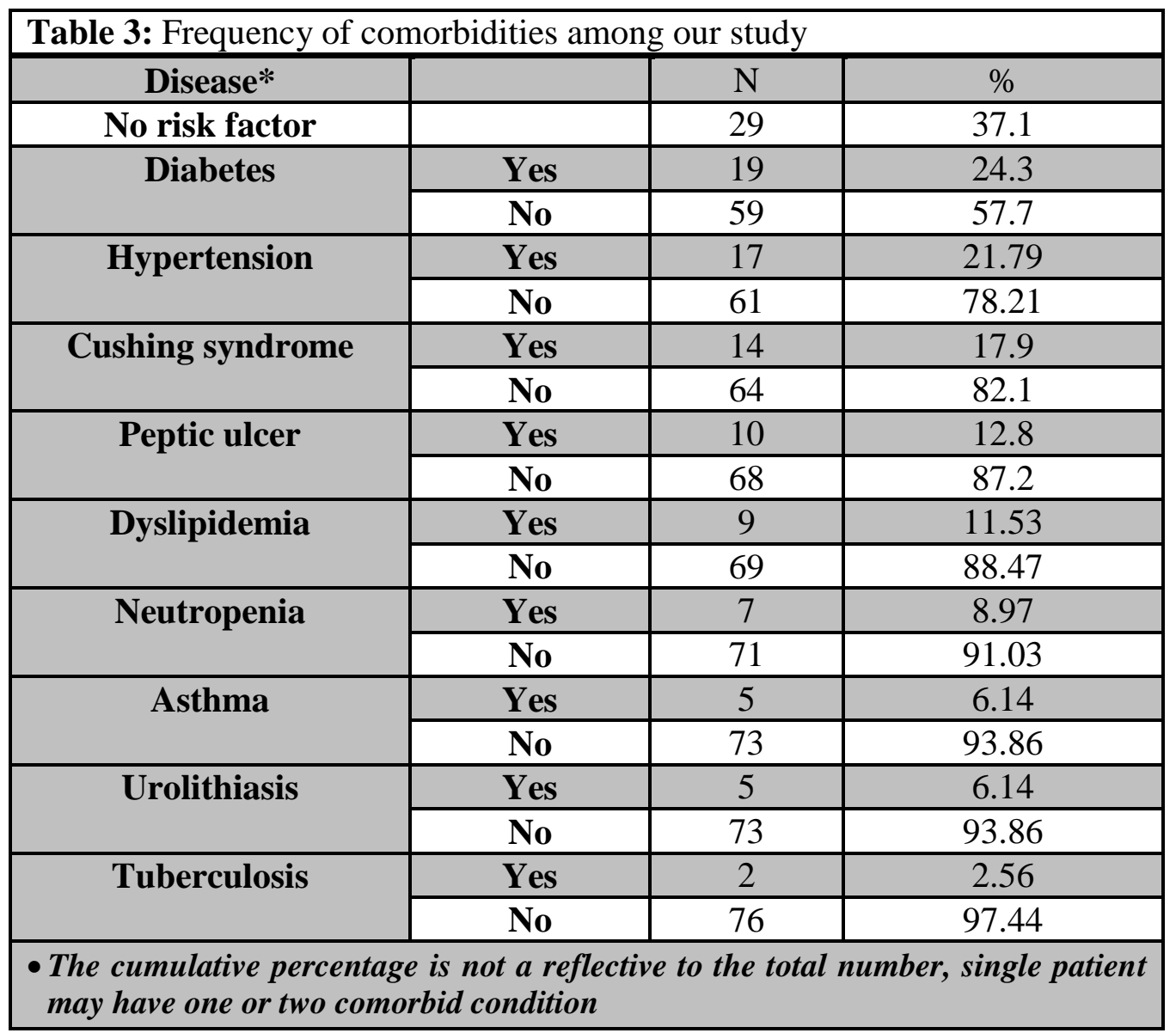

Table 4: Nosocomial infection vs. number of comorbidities.

\begin{tabular}{|l|l|l|l|}
\hline \multicolumn{3}{|l|}{ Comorbidity } & \\
\hline Nosocomial infection & $\mathbf{0 - 2}$ & $\mathbf{3 - 4}$ & Total \\
\hline Yes & $24(27.59 \%)$ & $45(51.72 \%)$ & $69(79.3 \%)$ \\
\hline No & $8(9.19 \%)$ & $1(1.14 \%)$ & $9(10.3 \%)$ \\
\hline & $32(36.78 \%)$ & $46(52.87 \%)$ & 78100 \\
\hline
\end{tabular}

Vol.(49); Iss.(12); No.(2); Dec..2020

ISSN 1110-0826 
Comorbid conditions may present as single factor or multiple factors in the same patient. Patients with nosocomial infections were found to have two or more comorbid conditions while infection-free cases were found to have no or at least one factor in a statistically significant association as in Table $4 \& 5$.

Disease spectrum

Primary diagnoses for which admission was made were varied. Fortyseven case was admitted due to traumatic brain injury. Twenty-two cases were admitted for postoperative neuro-oncological operation. The table 6 summarizes the primary diagnoses admitted in our ICU.

Table 5: Frequency of diagnoses in our study.

\begin{tabular}{|c|c|c|c|}
\hline & $\mathbf{N}$ & $\%$ & Total \\
\hline $\begin{array}{l}\text { Traumatic Brain injury (TBI) } \\
\text {-Acute epidural hematoma } \\
\text {-Acute subdural hematoma } \\
\text {-Chronic subdural hematoma } \\
\text {-Decompressive craniectomy for } \\
\text { malignant brain edema }\end{array}$ & $\begin{array}{l}48 \\
11 \\
18 \\
5 \\
14\end{array}$ & $\begin{array}{l}60.25 \\
14.1 \\
23.07 \\
6.41 \\
17.94\end{array}$ & \\
\hline $\begin{array}{l}\text { Nuero-oncology } \\
\text {-Benign brain tumors } \\
\text {-Malignant brain edema }\end{array}$ & $\begin{array}{l}7 \\
3 \\
4\end{array}$ & $\begin{array}{l}8.97 \\
3.84 \\
5.12\end{array}$ & \\
\hline Epilepsy surgery & 3 & 3.84 & \\
\hline $\begin{array}{l}\text { Surgically treated stroke } \\
\text {-Intracranial hemorrhage evacuation } \\
\text { or EVD* insertion } \\
\text {-Malignant edema treated by } \\
\text { decompressive craniectomy }\end{array}$ & $\begin{array}{l}16 \\
14 \\
2\end{array}$ & $\begin{array}{l}20.51 \\
17.94 \\
2.56\end{array}$ & \\
\hline $\begin{array}{l}\text { Traumatic spinal cord injury due to } \\
\text { fracture and treated by surgical } \\
\text { intervention }\end{array}$ & 5 & $6.41 \mathrm{~s}$ & \\
\hline
\end{tabular}

\section{EVD: external ventricular drain}


Journal of Environmental Sciences (JES)

Institute of Environmental Studies and Research, Ain Shams University

Shrief M. Salah El Deen et al.

It has been found that most cases with TBI and hemorrhagic stroke had nosocomial infection (74\%). Both types mentioned previously had longer ICU stay.

It has been found that nosocomial infection is commonly predominant in TBI and ICH cases with statistically significant value ( $\mathrm{p}=0.00005)$.

* Impact of Glasgow coma score (GCS)

The GCS was measured throughout admission till discharge. Putting a single numerical value for each patient would not respect the time as GCS is a dynamic with consciousness state. Hence, patients were categorized into minimal, mild, moderate, severe and critical consciousness. The minimal consciousness ranged from (14-15). Mild GCS was ranging from (13-10), moderate was ranging from (9-8), and severe was ranging from (7-4), while critical level was below 4. The bar graph (figure 1) summarizes the levels of consciousness in our study.

Value of mechanical ventilation

Some study participants were brought to be on mechanical ventilation. Indication of mechanical ventilation varied among our study sample. Patients with severe and critical GCS were hold on ventilation (22 patients). Fourteen patients were hold on mechanical ventilation due to hypoxia, severe bronchial secretions and acute respiratory distress syndrome. 
Journal of Environmental Sciences (JES)

Institute of Environmental Studies and Research, Ain Shams University

Shrief M. Salah El Deen et al.

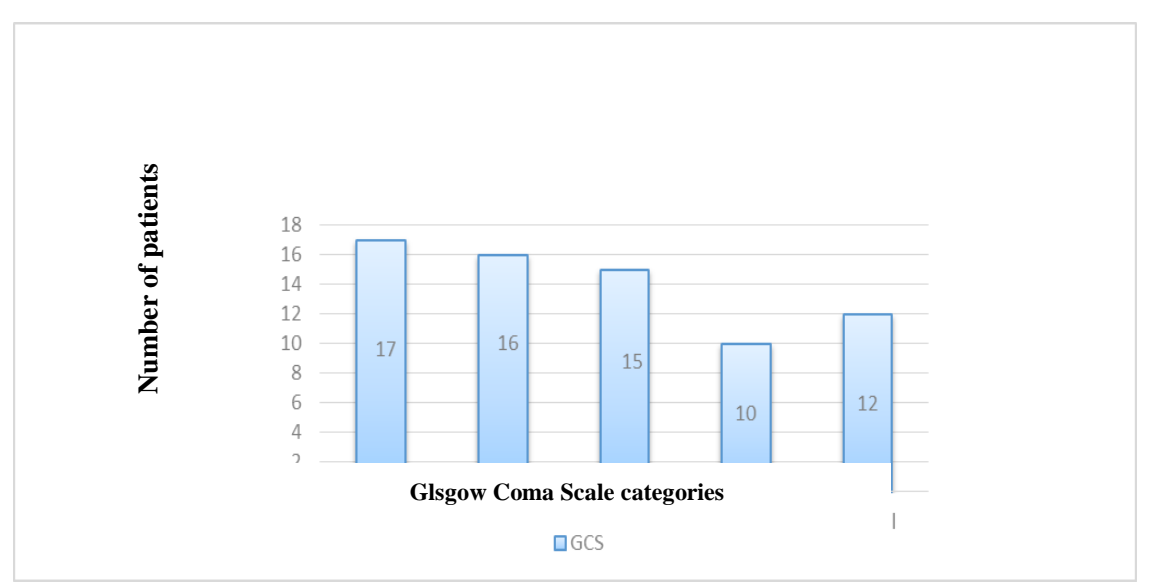

Figure 1: Glsgow Coma Scale categories among our study

* Positioning

Thirty-seven patients had low karnofsky score (40\% and below). At this level, patient are in need for frequent change in position. The rest of our study were above that level. The figure 2 summarizes the frequency. 


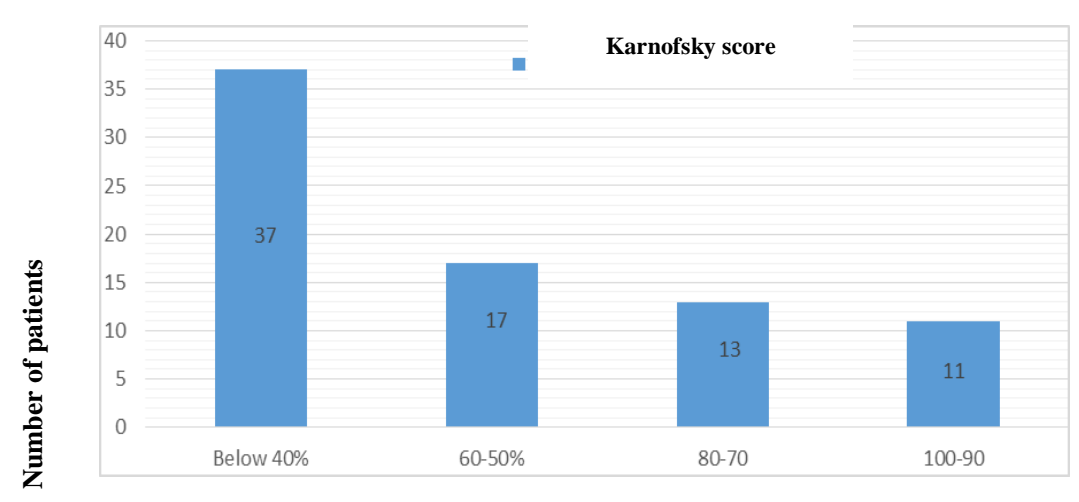

Figure 2: Grade of Karnofsky score

* Operative time

The operative time was calculated in minutes. The mean and standard deviation of operative time was 266.3 minutes \pm 52.4 . Operative time was mostly correlated with neurooncology cases. Lower operative time was mostly seen in traumatic brain injuries.

Nosocomial infection

Cases which have been diagnosed with nosocomial infection were 69 cases. Nosocomial infections were found to be either single or multiple infections in the same person. Most of infections were; respiratory tract infection, urinary tract infection or septicemia (Table 7). 
Table 7: Types of Nosocomial infection

\begin{tabular}{|c|c|c|}
\hline Type & N & $\%$ \\
\hline $\begin{array}{c}\text { Respiratory tract } \\
\text { infection }\end{array}$ & 44 & 56.4 \\
\hline Septicemia & 25 & 32.05 \\
\hline UTI & 20 & 25.6 \\
\hline Eye & 19 & 24.3 \\
\hline Surgical site infection & 15 & 19.23 \\
\hline $\begin{array}{c}\text { Catheter related } \\
\text { infection }\end{array}$ & 15 & 19.23 \\
\hline Gastrointestinal tract & 11 & 14.1 \\
\hline
\end{tabular}

* UTI: Urinary tract infection

\section{Microorganism isolated}

The most microorganisms isolated in all 69 patients were gram negative organisms $(67.9 \%)$. Gram positive bacteria were followed to be isolated in around $61.53 \%$. Fungal infections were found in 18 patients with urinary tract infection and esophagitis (mostly candida species). The table 8 below summarizes the frequencies.

Table 8: Types of microorganisms isolated

\begin{tabular}{|l|l|l|}
\hline Microorganism & $\mathbf{N}$ & $\mathbf{\%}$ \\
\hline Gram -ve & 53 & 67.9 \\
\hline Gram +ve & 48 & 61.53 \\
\hline $\begin{array}{l}\text { Anaerobic } \\
\text { infection }\end{array}$ & 19 & 24.35 \\
\hline Fungal infection & 18 & 23.07 \\
\hline
\end{tabular}


Microbial isolation sites were drained throughout admission. Sputum $(60.2 \%)$ followed by urine samples $(45.3 \%)$ were the most common sites for microbiological isolation followed by specimens taken from CVP or intravenous cannula.

Humidity and temperature

In our study, the ICU room humidiy (\%), nurse/bed ratio, area around patients and temperature were studied also. The table 9 contains the frequency distributions of such measures.

Table 9: Frequency distribution of nurse/bed ratio, area around patients, temperature (C) and humidity (\%).

\begin{tabular}{|l|l|l|c|}
\hline Factors & Minimum & Maximum & Mean \pm SD \\
\hline Nurse/bed ratio & 1.3 & 2.1 & $1.88 \pm 0.47$ \\
\hline $\begin{array}{l}\text { Area around } \\
\text { patient bed }\left(\mathbf{m}^{\mathbf{2}}\right)\end{array}$ & 9.3 & 15.6 & $11 \pm 2.75$ \\
\hline Temperature $(\mathbf{C})$ & 21.7 & 30.12 & $24.6 \pm 6.15$ \\
\hline Humidity $(\boldsymbol{\%})$ & 29.9 & 42.1 & $36.13 \pm 9.03$ \\
\hline
\end{tabular}

- Risk factors for colonization and nosocomial infection: Regression analysis

When the entire study population was subjected to logistic regression analysis, age, diagnosis and hospital stay, necessity for ventilation, high temperature, high humidity and low karnofsky were found to be significantly independently predictive of postoperative nosocomial infection (Table 10). Among these patients, type and timing of operative intervention and environmental factors did not significantly affect outcome 
Journal of Environmental Sciences (JES)

Institute of Environmental Studies and Research, Ain Shams University

Shrief M. Salah El Deen et al. 
Table 10: Independent predictors for ICU nosocomial infection

\begin{tabular}{|c|c|c|}
\hline Factors & Odd ratio & P value \\
\hline Age & 1.9 & 0.001 \\
\hline Disease & 0.2 & 0.0005 \\
\hline ICU stay & 3.7 & 0.0001 \\
\hline Mechanical ventilation & 4.1 & 0.00001 \\
\hline High Temperature & 4.5 & 0.00001 \\
\hline High Humidity & 3.9 & 0.0001 \\
\hline Low Karnofsky scale & 3.6 & 0.005 \\
\hline
\end{tabular}

\section{DISCUSSION}

The spread of nosocomial infections by traditional means such as lack of hand hygiene compliance goes as far back as the 1800s. The epidemiological findings of Dr. Ignaz Semmelweis helped to shed light on ways of controlling infections in a health care setting. By reviewing maternal deaths in two divisions of the maternity department in Vienna, Semmelweis noted that more than $10 \%$ of women died following childbirth when the baby was delivered by a physician or student in the first division, compared to a lower rate of $3 \%$ of maternal death when babies were delivered by a midwife. These differences in death rates could be explained by the fact that medical students and physicians performed autopsies without disinfecting their hands before attending to the next patient. In other words, the physicians were the source of infection to the patients. The midwives did not have any contact with cadavers. 
Journal of Environmental Sciences (JES)

Institute of Environmental Studies and Research, Ain Shams University

Shrief M. Salah El Deen et al.

The study aim was to evaluate risk factors and methods of infection control in surgical site infections in postoperative neurosurgical patients.

The number of nurses and environmental conditions affects the nosocomial infection rate in the ICU. Some authors reported that keeping not enough number of nurses increased the infection rate in the ICU (Zhao et al., 2017). Determine the ideal nurse number for preventing nosocomial infections in the ICU is difficult. The patients' clinical condition, the nurses' certification to work in the ICU, and some other factors are effective (Sheng et al., 2007).

The nurses trained about the ICU procedures are in better accordance with the infection control procedures compared with non trained (Ducel, J. Fabry, 2002).

A study showed that a nurse/patient ratio of more than 2.2 decreased the infection rate by $30 \%$ in the ICU (Nseir et al., 2012). The present study reported no statistically significant relationship between the infection rates and the nurse/patient ratio. The regulation about the nurse number working in the ICU is connected to the classification of the ICU in Turkey. If the ICU is a third degree, meant only for patients in a serious condition, it should have one nurse for every two patients in every shift. If the ICU is a second degree, it should have one nurse for every three patients in every shift (Hartholt et al., 2014).

The nurse/patient ratio reported in the present study was concordant with this regulation. This is the reason why no statistically significant relationship 
Journal of Environmental Sciences (JES)

Institute of Environmental Studies and Research, Ain Shams University

Shrief M. Salah El Deen et al.

of the nurse/patient ratio with the infection rates was found in the study. Future studies should consider not only the number but also the characteristics of nurses working in the ICU and investigate the quality factors affecting the nurse/patient ratio and infection rates, thus helping to establish new standards (Dancer, 2014).

The patients in the ICU are mostly in a bad clinical condition with numerous health problems and underlying diseases.

Their thermoregulation system is not working well enough. The changes in the room temperature affect the body temperature directly in the ICU patients. Therefore, the temperature and humidity should be maintained within specified limits in the ICU. The CDC environmental infection control guidelines state that the temperature should be between $20^{\circ} \mathrm{C}$ and $24^{\circ} \mathrm{C}$ and the humidity should be between $30 \%$ and $60 \%$ at the hospitals. The present ICU regulations specify that the temperature should be kept $22^{\circ} \mathrm{C}-28^{\circ} \mathrm{C}$ and the humidity should be $30 \%-60 \%$. The prevalence of some of the gramnegative bacterial infections, such as Acinetobacter spp., increases in the hot weather. Gram-negative bacteria infections are the problematic infections in the ICU because of their increasing resistance to antibiotics. The present study found no relationship of temperature and humidity with the infection rates [36.13 (29.9-42.1)]. The humidity was within limits [24.6 (21.7-30.12)], and the temperature exceeded the limits only for a short time. No major 
Journal of Environmental Sciences (JES)

Institute of Environmental Studies and Research, Ain Shams University

Shrief M. Salah El Deen et al.

differences in these measurements were found (Muñoz, Burillo and Bouza, 2001).

This was the reason why a relationship of temperature and humidity with the infection rates was not found. A statistically significant relationship was observed between humidity and catheter-related urinary tract infection rate in the present study. Few studies determined the relationship of increasing temperature and humidity with the nosocomial urinary tract infection caused by Pseudomonas aeruginosa. Some other studies linked urinary tract infections with high temperature and low humidity (Sheng et al., 2007).

The relationship between humidity and urinary tract infection needs to be further investigated before reaching any definite conclusions. The design of the ICU, having enough isolation rooms, area for each patient, and number of patients sharing the same room are related to the nosocomial infection rate. The area around the patient bed has a number of microorganisms. Therefore, the design of the room and the number of patient beds and surfaces in the room are important factors for infection control (Şimşek et al., 2017; Zhao et al., 2017).

An ideal ICU should have at least an area of $20 \mathrm{~m} 2$ with a single bed. The regulations about ICU beds specify at least $12 \mathrm{~m} 2$ for each bed and at least 1.5-m distance between the two beds. The present study reported a negative correlation between the infection rates in the ICU and the size of the patient bed. This is thought to be an important finding. Because of an increasing demand of ICU beds, accepting more patients in ICU rooms might 
Journal of Environmental Sciences (JES)

Institute of Environmental Studies and Research, Ain Shams University

Shrief M. Salah El Deen et al.

cause an increase in infection rates. Even if it is difficult to provide the ideal conditions, the compliance to the standards is important. At least the regulations related to the ideal conditions should not be disregarded ( $G$. Ducel, J. Fabry, 2002). Although the present study did not find any statistically significant relationship with the infection rates, it is still believed that the number and qualification of the nurses working in the ICU are important in preventing nosocomial infections. Beside the standard number, qualification standards should also be established. The distance between the patient beds is important for infection control. Hence, designing an ICU has increasing importance. Temperature and humidity can affect the nosocomial infection rates (Dancer, 2014).

Types of nosocomial infection [respiratory tract infection (56.4\%), septicemia (32.05\%), urinary tract infection (25.6\%), eye (24.3\%), surgical site infection (19.23\%), catheter related infection (19.23\%), gastrointestinal $\operatorname{tract}(14.1 \%)]$.

Types of microorganisms [Gram-ve organisms (67.9\%), Gram+ve organisms (61.53\%), anaerobic organisms (24.35\%), fungal (23.07\%).

Relation between nosocomial and comorbidities

In conclusion, there are many risk factors of nosocomial infection in hospitalized neurosurgical treated, which requires strengthening monitor, including the development of various effective prevention measures and 
Journal of Environmental Sciences (JES)

Institute of Environmental Studies and Research, Ain Shams University

Shrief M. Salah El Deen et al.

check of their implementation as well as effectiveness, to reduce the incidence of hospital infection.

Further studies are needed to investigate the exact relationship of internal and external factors with nosocomial infections in the ICU

The purpose of this research was to evaluate risk factors and methods of infection control in surgical site infections in postoperative neurosurgical patients.

This study was prospective, uncontrolled and observational study conducted on fifty sex patients with postoperative neurosurgical operation and admitted to ICU postoperatively. The study was done in Al-Azhar university hospitals from March 2017 to March 2018. The study aim was to evaluate risk factors and methods of infection control in surgical site infections in postoperative neurosurgical patients.

Analysis of data was done by IBM computer using SPSS (statistical program for social science version 25).

The mean age and standard deviation (SD) were 42.5 years \pm 19.1 . Male patients were prevalent in the sample. Forty-seven patients were male $(60.25 \%)$. Most male patient were above median age of the sample (37.8 years).

The overall admission period contains pre-ICU admission, ICU admission and post-ICU admission. The mean and standard deviation of overall admission was 43.7 day \pm 5.5 . The distribution of values was not 
Journal of Environmental Sciences (JES)

Institute of Environmental Studies and Research, Ain Shams University

Shrief M. Salah El Deen et al.

normal. Two patients were regarded as outliers with longstanding period in ICU up to 3 months.

It has been found that cases with positive infection (nosocomial infections) were statistically significant associated with long ICU stay $(p=0.0025)$. Patients who never developed nosocomial infections had shorter ICU stay $(\mathrm{p}=0.0001)$.

From the whole study sample, nosocomial infection was estimated to be $88.4 \%$ of cases (69 patients). Postoperative mortality among cases was $36 \%$. The rest of cases were either referred or discharged to ward.

Comorbid conditions may present as single factor or multiple factors in the same patient. Patients with nosocomial infections were found to have 2 or more comorbid conditions while infection-free cases were found to have no or at least one factor in a statistically significant association.

It has been found that most cases with TBI had longer ICU stay.

It has been found that nosocomial infection is commonly predominant in TBI and ICH cases.

The GCS was measured throughout admission till discharge. Putting a single numerical value for each patient would not respect the time as GCS is a dynamic with consciousness state. Hence, patients were categorized into minimal, mild, moderate, severe and critical consciousness. The minimal consciousness ranged from (14-15). Mild GCS was ranging from (13-10), 
Journal of Environmental Sciences (JES)

Institute of Environmental Studies and Research, Ain Shams University

Shrief M. Salah El Deen et al.

moderate was ranging from (9-8), and severe was ranging from (7-4), while critical level was below 4 .

Cases which have been diagnosed with nosocomial infection were 69 cases. Nosocomial infections were found to be either single or multiple infections in the same person. Most of infections were; respiratory tract infection, urinary tract infection or septicemia.

When the entire study population was subjected to logistic regression analysis, age, diagnosis and hospital stay, necessity for ventilation, low GCS, high temperature, high humidity and low karnofsky were found to be significantly independently predictive of postoperative nosocomial infection. Among these patients, type and timing of operative intervention and environmental factors did not significantly affect outcome.

\section{CONCLUSION}

There are many risk factors of nosocomial infection in hospitalized neurosurgically treated, which requires strengthening monitor, including the development of various effective prevention measures and check of their implementation as well as effectiveness, to reduce the incidence of hospital infection. 
Journal of Environmental Sciences (JES)

Institute of Environmental Studies and Research, Ain Shams University

Shrief M. Salah El Deen et al.

\section{REFERENCES}

Abulhasan, Y. B. et al. (2018) 'Healthcare-associated infections in the neurological intensive care unit: Results of a 6-year surveillance study at a major tertiary care center.', American journal of infection control. United States, 46(6), pp. 656-662. doi: 10.1016/j.ajic.2017.12.001.

Beer, R., Pfausler, B. and Schmutzhard, E. (2010) 'Infectious intracranial complications in the neuro-ICU patient population.', Current opinion in critical care. United States, 16(2), pp. 117-122. doi: 10.1097/MCC.0b013e328338cb5f.

Cardoso, T. et al. (2015) 'Microbiology of healthcare-associated infections and the definition accuracy to predict infection by potentially drug resistant pathogens: a systematic review.', BMC infectious diseases. England, 15, p. 565. doi: 10.1186/s12879-015-1304-2.

Dancer, S. J. (2014) 'Controlling hospital-acquired infection: Focus on the role of the environment and new technologies for decontamination', Clinical Microbiology Reviews, 27(4), pp. 665-690. doi: 10.1128/CMR.00020-14.

DM, F. et al. (2010) 'An assessment of the effect of statin use on the incidence of acute respiratory infections in England during winters 1998-1999 to 2005-2006.', Epidemiology \& Infection, 138(9), pp. 1281-1288. doi: 10.1017/S0950268810000105.

G. Ducel, J. Fabry, L. N. (2002) 'Prevention of hospital-acquired infections.', World Health Organization, pp. 1-64. doi: WHO/CDS/CSR/EPH/2002.12.

Hartholt, N. L. et al. (2014) 'Preoperative statin therapy and infectious complications in cardiac surgery', Netherlands Heart Journal, 22(11), pp. 503-509. doi: 10.1007/s12471-014-0581-5.

Muñoz, P., Burillo, A. and Bouza, E. (2001) 'Environmental surveillance and other control measures in the prevention of nosocomial fungal infections', Clinical Microbiology and Infection, 7, pp. 38-45. doi: 10.1111/j.1469-0691.2001.tb00008.x. 
Nseir, W. et al. (2012) 'The impact of prior long-term versus short-term statin use on the mortality of bacteraemic patients', Infection, 40(1), pp. 41-48. doi: 10.1007/s15010-011-0190-9.

Sheng, W. H. et al. 'Risk factors affecting in-hospital mortality in patients with nosocomial infections', Journal of the Formosan Medical Association. Formosan Medical Association \& Elsevier, 106(2), pp. 110-118. doi: 10.1016/S0929-6646(09)60226-6. (2007)

Şimşek, E. M. et al. 'Relationship between Environmental Conditions and Nosocomial Infection Rates in Intensive Care Unit', Medical Journal of Islamic World Academy of Sciences, 25(1), pp. 15-18. doi: 10.5505/ias.2017.66742(2017).

Zhao, X. et al. (2017) 'Risk factors and prevention counter measures of nosocomial infection in', 28(21), pp. 9429-9433. 


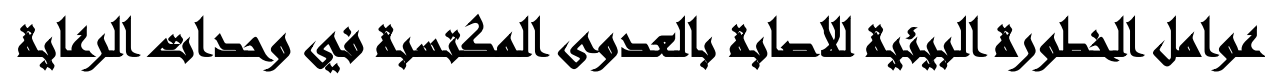

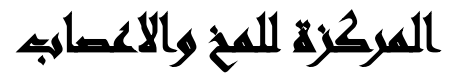

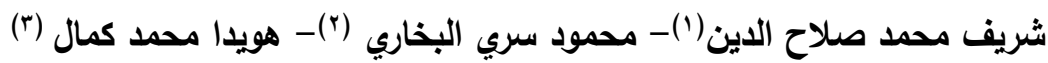

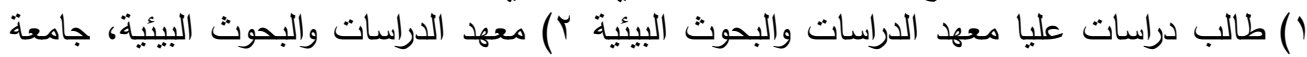
عين شمس ץ) كلية طب، جامعة بنها

\section{المستخلئ}

إن العدوى المكتسبة في الرعاية المركزة لمرضى جراحة المخ والاعصداب قد تؤدي الى زيادة فترة

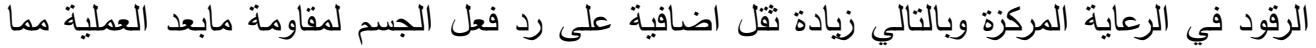
يوهن صحة المريض وقد يؤدي الى الوفاة.

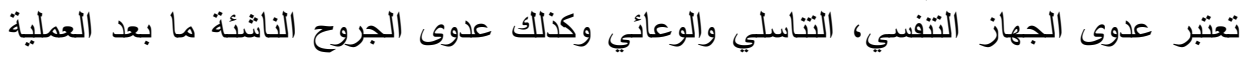
وقرح الفراش من اشكال العدوى البكتيرية محل الدراسة.

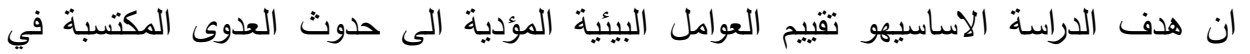

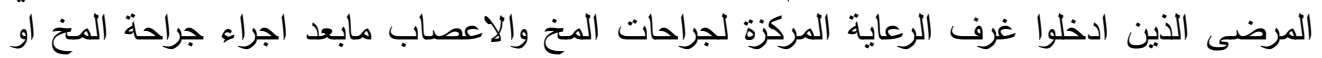
العمود الفقري وطرق مكافحة هذه العدوى بكافة الشكالها.

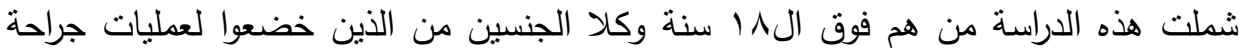

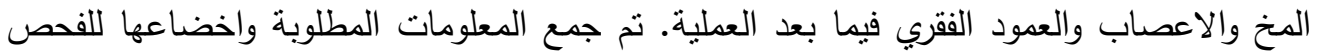

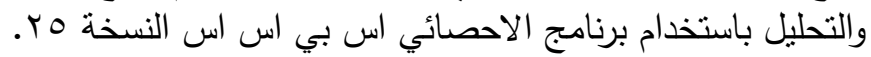

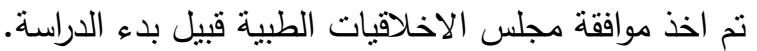
تعتبر هذه الدراسة دراسة مسبقة، مسحية ولا تتضمن وجود مجموعة سيطرة فيها. اقيمت هذاته

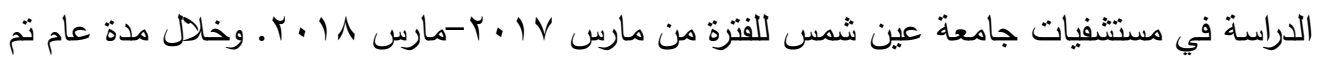

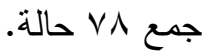

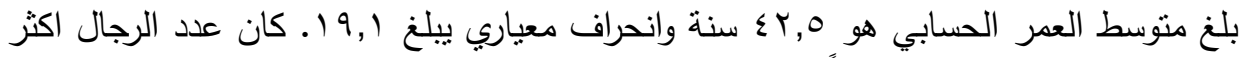

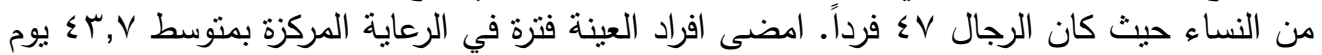

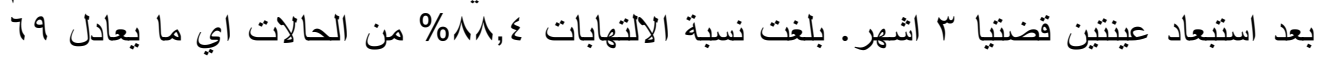

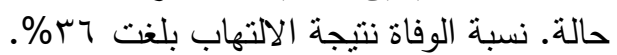

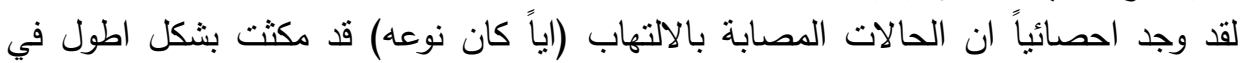
الرعاية المركزة عن تلك الحالات الني الحات لم تصب. 
Journal of Environmental Sciences (JES)

Institute of Environmental Studies and Research, Ain Shams University

عندما تم اخضاع المتغيرات ذات العلاقة الترابطية مع حالة الالتهاب لدراسة الاتحدار بين

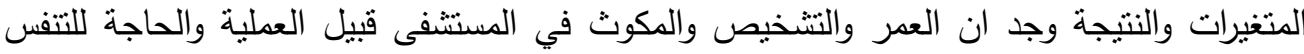

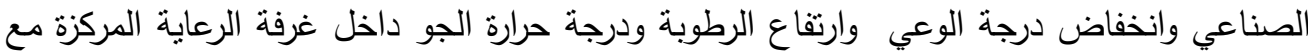

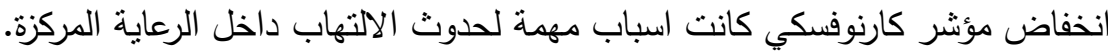

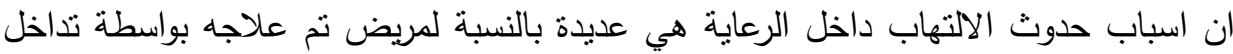

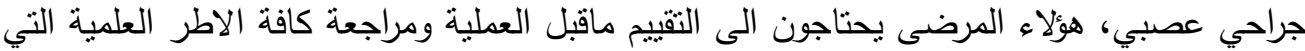
على اساسها يتم معالجة المريض في الرعاية المركزة والمتعلقة بدرجة الحرارة والرطوبة وعدد الإسرة

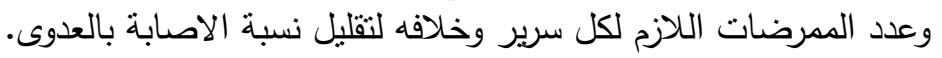

